\title{
Stable isotopes in tree rings from the Russian Arctic- a proxy for winter precipitation?
}

Steffen Holzkämper and Peter Kuhry

Department of Physical Geography and Quaternary Geology, Stockholm University, Sweden; steffen.holzkamper@natgeo.su.se

\section{Stable carbon and oxygen isotopes in tree rings from the NE European Russian Arctic are closely related to measured winter precipitation.}

Dendroclimatology studies shed light on the climate conditions prior to the instrumental data period. The classical approach is to derive past summer temperatures from the tree ring width or more recently, from tree ring density. By studying stable carbon and oxygen isotopes in tree ring cellulose, additional climate parameters may be retrieved, though the underlying mechanisms and relations between climate and tree ring isotopes are complex and may vary for different locations (McCarroll and Loader, 2004).

\section{Study area}

The Moreju River, located in NE European Russia (Fig. 1), lies in the transition zone of continuous to discontinuous permafrost. The area can be described as lowland tundra dominated by wetland vegetation, willow bushes, dwarf shrubs and lichens. The river system is eroded into the lowland plain and the relief between the river level and the surrounding plain ranges from $5-20 \mathrm{~m}$. In one valley incision, we found a small forest patch with 10-12 m high trees that survive due to the local absence of permafrost near the riverbank and favorable microclimate conditions. In summer 2004, we collected Siberian spruce (Picea obovata) samples from this forest island, $\sim 80 \mathrm{~km}$ from the Barents Sea coast $\left(68.1^{\circ} \mathrm{N}, 60.0^{\circ} \mathrm{E}\right)$. The climate in the study area is Arctic, with mean annual temperatures around $-5^{\circ} \mathrm{C}$ and annual precipitation $\sim 450 \mathrm{~mm}$. Five climate stations lie within 200-500 km of the study site (Fig. 1), with the longest of the monitoring records extending back to AD 1883. Analysis of the observed meteorological data shows that climate is highly correlated between the sites. Thus it can be assumed that the climate conditions impacting the Moreju River are similar to those measured at the weather stations, especially given that the regional landscape is flat (Holzkämper et al., 2008).

The amount of snow falling during the winter time is an important parameter for the growth of trees. A thick snow cover is likely to melt away late in spring, consequently shortening the growing season, especially the early period of rapid growth (Vaganov et al., 1999). On the other hand, snow cover protects young seedlings from wind abrasion and extremely cold temperatures, and thus provides a positive effect on the growth of younger trees. Past snow depths can be approximated from winter precipitation records, i.e., for the months November to April, when the average temperatures are well below $0^{\circ} \mathrm{C}$. A comparison of monthly winter precipitation with the observed snow depth at the climate station of Khoseda Khard (Fig. 1) confirms that winter precipitation is regionally recorded with sufficient accuracy.

\section{Methods}

Isotopes were analyzed from three trees from the study area (Holzkämper et al., 2008). The tree ring record spans from AD 1864-2003. For the analysis, wood from single tree rings was cut from discs, a-cellulose was extracted and isotope ratios were measured. The $\delta^{13} \mathrm{C}$ data were corrected for the decrease in atmospheric $\delta^{13} \mathrm{C}$ values due to the rise in $\mathrm{CO}_{2}$ caused by fossil fuel combustion since the beginning of industrialization (Francey et al., 1999). All tree ring series were quality checked and detrended using standard procedures (Holmes et al., 1986). The correlations between the resulting tree ring width index, $\delta^{18} \mathrm{O}, \delta^{13} \mathrm{C}$ and observed monthly air temperature and precipitation were calculated.

\section{Results}

No consistent correlation between tree ring width and air temperatures was found in the analyzed trees. Significant anti-correlations (95\% significance level), however, were observed between tree ring width from one year and the precipitation that fell during the preceding winter months (Nov-Apr) in 2 out of 3 trees (Fig. 2a,b; see Holzkämper et al., 2008 for more details).

The $\delta^{13} \mathrm{C}$ data (Fig. 2c) of the individual trees show a rather weak correlation pattern with temperature. On the other hand, there is a significant positive correlation between $\delta^{13} \mathrm{C}$ and winter precipitation in one of the analyzed trees. The carbon isotope composition in tree rings depends on the rate of photosynthesis (carboxylation) and stomatal conductance. These can be influenced by a number of parameters, among which air humidity, temperature and soil moisture status are the most important. Therefore it is not surprising that $\delta^{13} \mathrm{C}$ values between different trees do not express exactly the same variability and that not all trees show the same dependence on winter precipitation. Site specific conditions, such as the depth of the groundwater table, surrounding vegetation and wind exposure may enhance or weaken the influence of snow depth on the stable isotope value of the tree ring cellulose.

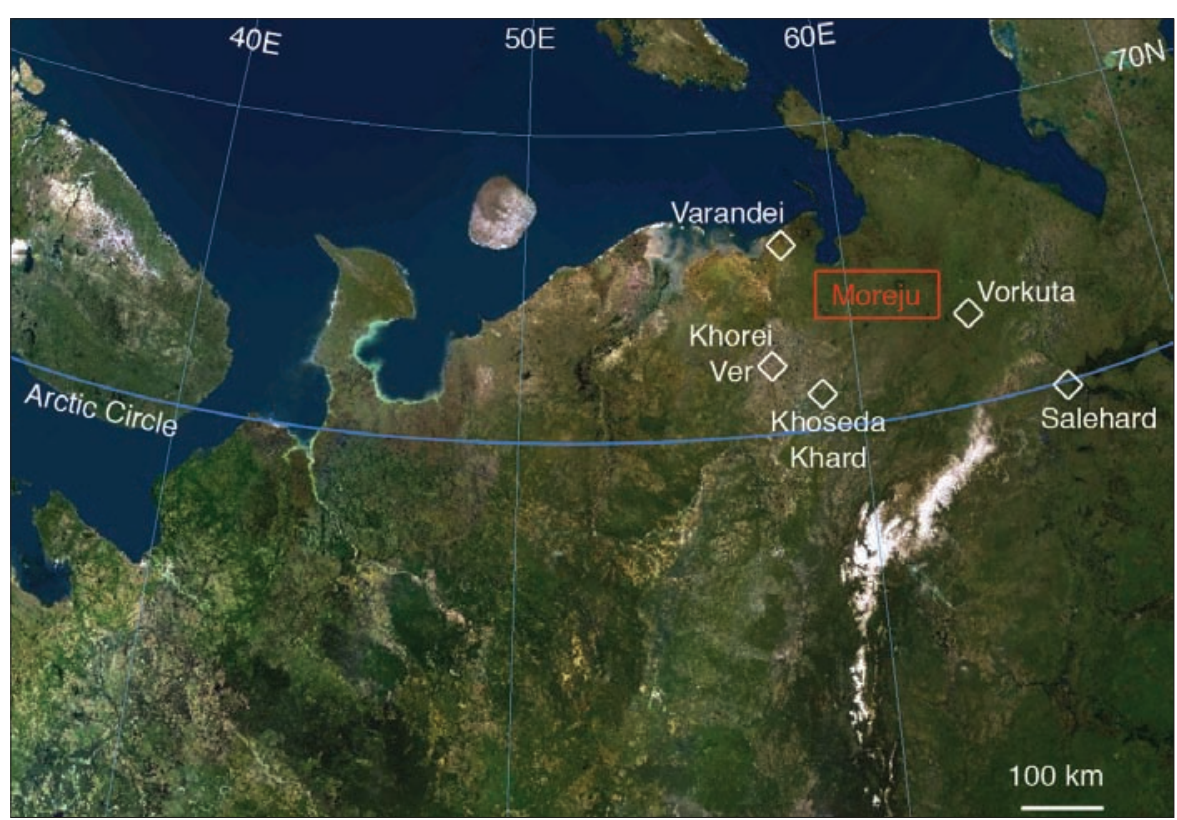

Figure 1: Map showing location of study site (Moreju) and surrounding climate stations (white diamonds). Map provided by United Soft Media Verlag GmbH. 
The $\delta^{18} \mathrm{O}$ composition of tree rings depends on the oxygen isotope ratio in the source water (precipitation), as well as on processes in the soil and in the tree. Important parameters are ground-based evaporation and transpiration in the leaves, leading to an enrichment of ${ }^{18} \mathrm{O}$. Other relevant factors are the water vapor source, which might have changed over time, recycling of moisture from the landscape, cloud track and fallout histories of the water vapor reaching the site, and the temperature during precipitation (Kohn and Welker, 2005).

A positive correlation between $\delta^{18} \mathrm{O}$ (Fig. 2c) of the individual trees and the temperature of different months can be observed but the patchy distribution of the correlated months indicates that the influence of temperature is small. On the other hand, the precipitation amount of the previous winter months explains a large portion of the observed variability. For example, correlation coefficients around -0.5 were calculated for the months November to February for the tree that also showed a positive correlation between $\delta^{13} \mathrm{C}$ and winter precipitation. It is likely that winters with a thick snow cover that is depleted in ${ }^{18} \mathrm{O}$ will result in relatively low soil moisture $\delta^{18} \mathrm{O}$ values; in turn these oxygen isotopes are incorporated into the ring cellulose during the next year's growth season. As discussed before, site specific conditions make the isotope values more or less sensitive to changes in the thickness of the winter snow pack.

In summary, the thickness of the snow cover and the timing of snow melt have a strong impact on ring width and the $\delta^{13} \mathrm{C}$ and $\delta^{18} \mathrm{O}$ composition of the ring cellulose, as the early summer months are most critical for wood formation. Cellulose isotopes may therefore be used as a proxy

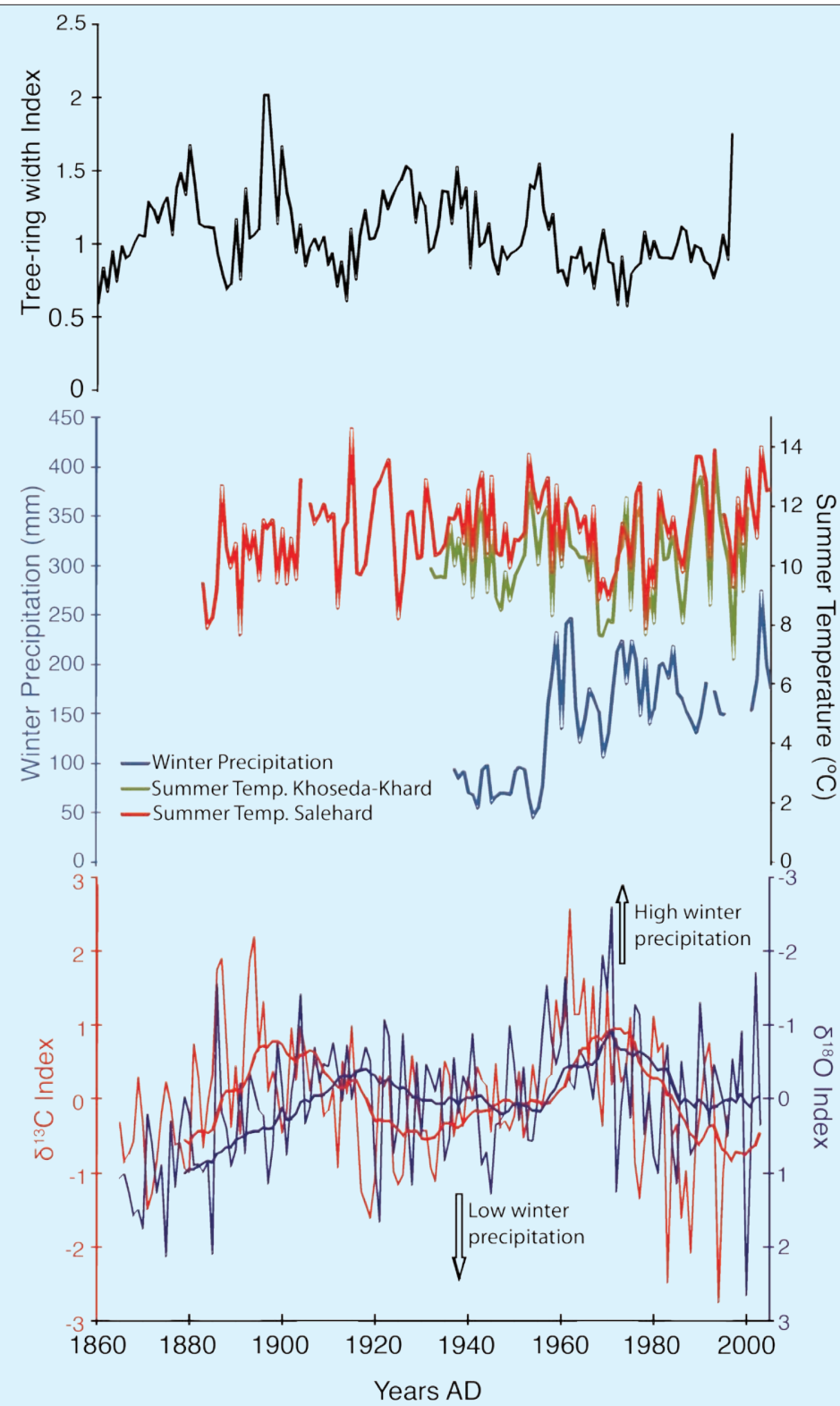

Figure 2: a) Tree ring width index (standardized average of the 3 study trees). b) Summer temperature (Jun-Aug) of Khoseda-Khard (green), and Salehard (red) weather stations, and average winter precipitation (Nov-Apr) of Vorkuta, Khorei-Ver and Khoseda-Khard weather stations (blue; data from Russian Weather Service). c) Comparison between the $\delta^{18} \mathrm{O}$ index and $\delta^{13} \mathrm{C}$ index (with running means, index is the standardized average isotope value of the trees). Note inversed $y$-axes, thus peaks (troughs) represent high (low) winter precipitation. for winter precipitation, provided that the site specific conditions are sufficiently well understood.

\section{Prospects}

Interpreting the stable carbon and oxygen isotope ratios extracted from tree ring cellulose can be used to reconstruct past climate and environmental changes, as revealed by the relatively high correlation coefficients with the observed climate. Which climate parameter is actually recorded by the stable isotopes is, however, dependent on site-specific conditions and has to be evaluated by comparison with observed meteorological data. The advantage of isotopes over ring width data is the absence of any biologically induced aging trend that disturbs the low frequency climate signal from the ring width curves. Also, they may add information about climate parameters, such as winter precipitation and snow cover. However, the complexity of processes that influence the isotope composition of the ring cellulose is large and requires better understanding. More isotope data from tree rings will help to shed light on the underlying processes, and modeling approaches and data from other climate archives from the same region, such as lake sediments and stable isotopes in single moss species in peat, are needed to decipher the different mechanisms acting on different temporal and spatial scales.

\section{Note}

All data produced by the project will be stored with NOAA/NGDC (www.ncdc.noaa.gov/paleo/ paleo.html) and PANGAEA/WDC-MARE (www. pangaea.de/) and contribute to the PAGES Arctic2k Project (www.pages-igbp.org/science/ $\operatorname{arctic} 2 \mathrm{k} /$ ).

\section{Acknowledgements}

The study was financed by the EU-GLIMPSE Project (contract EVK2-CT-2002-00164) and EUCARBO-North Project (contract 036993).

\section{References}

Francey, R.J., Allison, C.E., Etheridge, D.M., Trudinger, C.M., Enting, I.G., Leuenberger, M., Langenfelds, R.L., Michel, E. and Steele, L.P. 1999: A 1000-year high precision record of $\delta^{13} \mathrm{C}$ in atmospheric $\mathrm{CO}_{2}$, Tellus, 51B: 170-193.

Holzkämper, S., Kuhry, P., Gunnarson, B., Kultti, S., Sonninen, E., 2008 Stable isotopes in tree rings as proxies for winter precipitation changes in the Russian Arctic over the past 150 years, Geochronometria, 32 (accepted, pending minor revisions).

Kohn, M.J. and Welker, J.M., 2005: On the temperature correlation of $\delta^{18} 0$ in modern precipitation, Earth and Planetary Science Letters, 231: 87-96.

McCarroll, D. and Loader, N.J., 2004: Stable isotopes in tree rings, Quaternary Science Reviews, 23: 771-801.

Vaganov, E.A., Hughes, M.K., Kirdyanov, A.V., Schweingruber, F.H. and Silkin, P.P., 1999: Influence of snowfall and melt timing on tree growth in subarctic Eurasia, Nature, 400: 149-151.

For full references please consult:

www.pages-igbp.org/products/newsletters/ref2009_1.html 